\title{
Evaluation of Surface Materials for Pavements and Footpaths
}

\author{
Vincas Gurskis, Rytis Skominas, Giedrius Sakalinskas, Aleksandras Stulginskis University, \\ Lithuania
}

\begin{abstract}
Scientific studies, standards and regulations regarding the requirements for design, construction, exploitation and maintenance of pavements and footpaths were analysed during the research. The main problems which appear during the construction and exploitation of these engineering structures were also studied. Estimating the most optimal surface material for pavements and footpaths, the most popular materials (asphalt, site-cast concrete, concrete slabs, concrete blocks, clinker blocks, stone blocks and gravel) were analysed. Evaluating different surface materials, the parameters were taken from a survey. In this survey the designers of pavements and footpaths as well as constructors participated. The public opinion was also taken into account. For the estimation of optimal surface material multicriteria analysis software Visual Promethee was used. The analysis shows that the most optimal surface material for pavements and footpaths is concrete blocks.
\end{abstract}

Keywords: pavement, footpath, surface material.

\section{Introduction}

Pavements and footpaths are very important engineering structures in communication nets for walkability [3]. According to Tim Massart [5] walking and cycling are green transport modes which will get more attention in the future. Therefore, during the development of an infrastructure it is necessary that pavements and footpaths get more attention. N. Stevens and P. Salmon [7] offer that footpath design efforts should consider the overall foot-path system and the intertwined functional purposes of providing safety and a sense of place. Urban planning needs new ways to interpret built environments as not only technical systems, but often poorly understood (and designed) socio-spatial systems. This cooperative effort between Human Factors and Urban Planning disciplines should be allowed for new insights into the development of more pedestrian orientated footpath environments.

Unfortunately, in some Eastern Europe countries pavements and footpaths are not being repaired or reconstructed due to lack of finances, there are no enough money for making new pavements and footpaths. Lithuania has the same problems too. One of the possibilities to prevent defects is to create a special application on smartphone for reporting defects. The user can enter in detail any defect or remark with GPS coordinates, a picture, and some comments. City authorities using this method will have a lot of valuable data at their disposal to make informed decisions for footway modifications and maintenance [5].

According to the Italian researchers [2] it is necessary to record the flow of people, and afterwards, according to this data it is possible to estimate problematic places, to select priorities for reconstruction of pavements and footpaths.

Unfortunately, in Lithuania, like in some others EU countries, there are no rules regarding the construction of pavements and footpaths. In Lithuania the pavements and footpaths are designed according to the following recommendations: "Pedestrian and bicycle path design guidelines" [6]. Of course, the new designed or reconstructed pavements and footpaths must meet the requirements for people with disabilities listed in the document "Technical Construction Regulation STR 2.03.01:2001 Structure and territories. Requirements for people with special needs". This social group is particulary sensitive in terms of using improperly constructed pavements and footpaths. According to the World Health Organization [10] 253 million people live with vision impairment: 36 million are blind and 217 million have moderate to severe vision impairment. Therefore, when constructing new or reconstructing old pavements and footpaths it is necessary that they meet the requirements for these people.

In Lithuania's regulations there are only basic requirements for pavements and footpaths: a cross slope $0.5 \ldots 3 \%$, longitudinal slope $\leq 4 \%$ (in special places $\leq 8 \%$ ), the width for 1 person $\geq 1 \mathrm{~m}$, the width for 1 person with disabilities $\geq 1.2 \mathrm{~m}$, the height $\geq$ $2.25 \mathrm{~m} \mathrm{[6].} \mathrm{Unfortunately,} \mathrm{the} \mathrm{pavements} \mathrm{and}$ footpaths constructed during the Soviet period did not meet these requirements (Fig. 1). The poor technical state of pavements and footpaths constructed during that period was affected by many factors: low quality base and subbase (too thin of layers, inadequate density of compacted layers, inappropriate slopes, not suitably embeded kerbs, too low frost resistance of surface materials.

The pavements and footpaths are constructed similarly to the roads: removal of vegetative layer, if necessary the subgrade formation, subbase layer (resistant for freezing - thawing) formation, base layer formation and surface layer construction. In the last layer, builders (including municipalities) who are constructing new or reconstructing old pavements and footpaths have a problem as to which surface 
material to select. The surface material must be durable, aesthetic and simply exploited. Therefore, it is necessary to compare different materials. It is possible to find studies about the effect of walking sounds from different walked-on materials on people's soundscape [1], [4]. However, the studies about other properties are insufficient. Thus, the aim of this work was to estimate the most optimal surface material for pavements and footpaths.

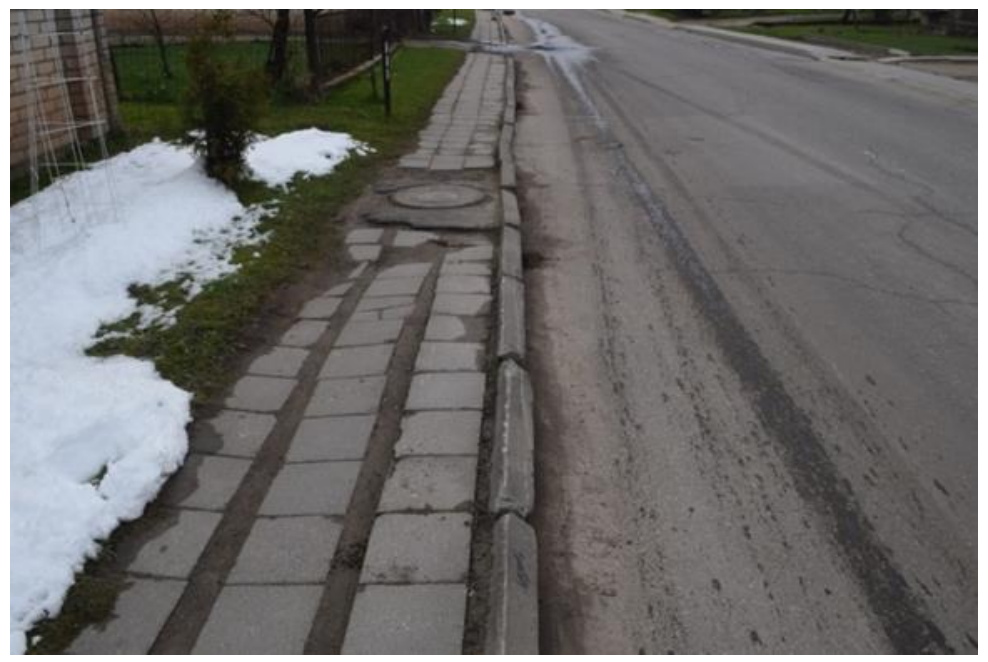

Fig. 1. Pavement constructed during the Soviet period

\section{Methodology}

As a research object seven most popular surface materials used for pavements and footpaths were chosen: asphalt, site-cast concrete, concrete slabs, concrete blocks, clinker blocks, stone blocks and gravel. All these materials have different properties and it is hard to estimate which material is the best. Therefore, multi-criteria analysis was selected for the evaluation of the materials.

For multi-criteria analysis data were gathered from the specialist surveywhose participants were the employees from the Lithuanian Road Administration under the Ministry of Transport and Communications, State Territorial Planning and Construction Inspectorate under the Ministry of Environment, Departments of Architecture and Urbanism of Municipalities, heads of construction, designers and technical supervisors. The questionnaire was anonymous. Ten criteria were selected for the evaluation of surface materials: durability, versatility, aesthetics, resistance to mechanical or chemical attack, possibility to repair and reconstruct, exploitation costs, labour mechanization level, safety in use, variety of colours and shapes as well as supply. All criteria were evaluated on a 10 points system: 10 - excellent, 1 very poor. If a questionnaire was filled in a perfunctory manner, with mistakes or partly they were denied.

The public opinion about surface materials of pavements and footpaths was also taken into account. For this purpose, a second survey was conducted. In this survey there were two main questions: which surface material is the best and which criterion is the most important.
The main factor for the surface material selection is cost. Cost is the main criterion in public procurement. Therefore, the municipalities are constrained to choose the least expensive variants (with the least expensive surface materials of pavements and footpaths). To evaluate this criterion an economic calculation for construction was done using the SES 2004 software. During the calculations the construction cost of $100 \mathrm{~m}^{2}$ surface material with first layer (without kerbs) was estimated including all taxes valid in Lithuania.

Another very important criterion is durability. This criterion depends on many factors: material characteristics, exploitation, environmental impact, etc. Durability can be described by lifetime. The lifetime in this research was estimated according to the date given in the "Technical Construction Regulation STR 1.12.05:2002 Usage and lifetime of the structure" document.

For multi-criteria analysis the software Visual Promethee was selected. Visual Promethee is multicriteria decision aid software. It includes many approaches, models and methods to handle decision or evaluation problems where multiple evaluation criteria have to be taken into account. Three main methods in the Visual Promethee software are used: Multi-criteria Table, Aggregation and Weighted Sum and Outranking Methods [11].

Analysing the data with Visual Promethee software, three tests were performed: with equal criteria and with dominant criterion. Cost and aesthetics were selected as the dominant criteria. They had two times higher of a score than others. 


\section{Test results}

According to the specialists' opinion (Table 1) the most durable and resistant to environmental impact surface material for pavements and footpaths is stone blocks and the weakest material is gravel, which has the shortest lifetime before repair. The most versatile material is asphalt and it can be used almost in all cases, while the gravel has a reverse evaluation - it is suitable in only some cases. Specialists think that the most aesthetic material and which has the widest variety of colours, is clinker blocks and gravel was evaluated as the worst material. According to the possibility to be repaired and reconstructed, concrete blocks got the highest evaluation due to the possibility to replace separate blocks having defects. The site-cast concrete received the lowest evaluation due to the complicated repair technology of concrete.
Exploitation costs are the highest in gravel pavements and footpaths and the lowest in pavements and footpaths with stone block surface material. The fastest construction process is associated with using asphalt due to the labour mechanization level, while the longest construction process is associated with using stone blocks due to the high amount of manual labour and the irregular form of blocks. Regarding one essential requirement "Safe in use" the specialists think that the safest surface material is asphalt and the least safe stone blocks due to the possibility to slip or stumble. Gravel got the highest evaluation in terms of supply due to the large number of quarries in Lithuania. The stone blocks as a non-natural resource of Lithuania received the lowest evaluation.

Specialists survey results

\begin{tabular}{|c|c|c|c|c|c|c|c|c|c|c|}
\hline 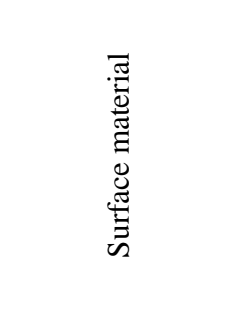 & 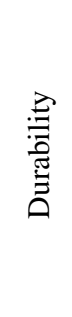 & 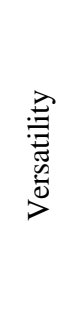 & 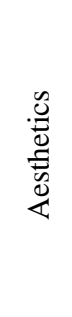 & 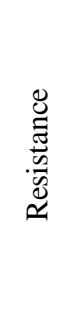 & 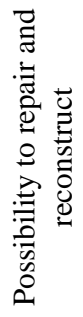 & 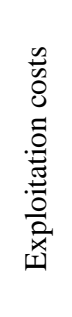 & 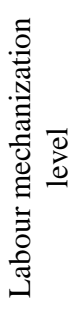 & 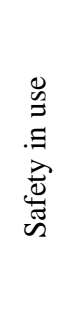 & 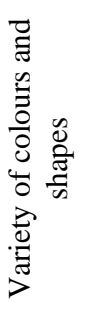 & 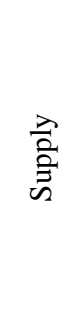 \\
\hline Asphalt & 8.09 & 9.32 & 7.03 & 7.65 & 7.09 & 7.74 & 8.71 & 8.29 & 3.00 & 7.35 \\
\hline Site-cast concrete & 6.24 & 7.59 & 6.09 & 6.41 & $\underline{5.76}$ & 6.76 & 7.18 & 7.41 & 3.97 & 8.29 \\
\hline Concrete slabs & 6.88 & 7.15 & 7.18 & 6.65 & 8.00 & 7.26 & 6.29 & 6.88 & 5.94 & 7.91 \\
\hline Concrete blocks & 8.06 & 7.97 & 8.59 & 8.00 & 8.53 & 7.74 & 6.56 & 7.53 & 8.35 & 7.94 \\
\hline Clinker blocks & 8.24 & 7.76 & 9.41 & 7.88 & 8.21 & 7.56 & 6.35 & 6.82 & 8.85 & 5.82 \\
\hline Stone blocks & 9.26 & 6.15 & 9.24 & 9.21 & 8.09 & 8.15 & $\underline{6.09}$ & $\underline{6.47}$ & 6.59 & $\underline{5.38}$ \\
\hline Gravel & $\underline{4.82}$ & $\underline{4.82}$ & $\underline{3.88}$ & $\underline{4.65}$ & 8.38 & $\underline{5.38}$ & 8.12 & 7.00 & $\underline{2.18}$ & 9.47 \\
\hline
\end{tabular}

According to public opinion (Fig. 2) the top 3 surface materials for pavements and footpaths are concrete blocks $(37.3 \%)$, clinker blocks $(23.5 \%)$ and stone blocks $(23.5 \%)$. The most undesirable surface material is gravel $(0.01 \%)$. Therefore, it can be stated that people mostly like durable and aesthetic materials.
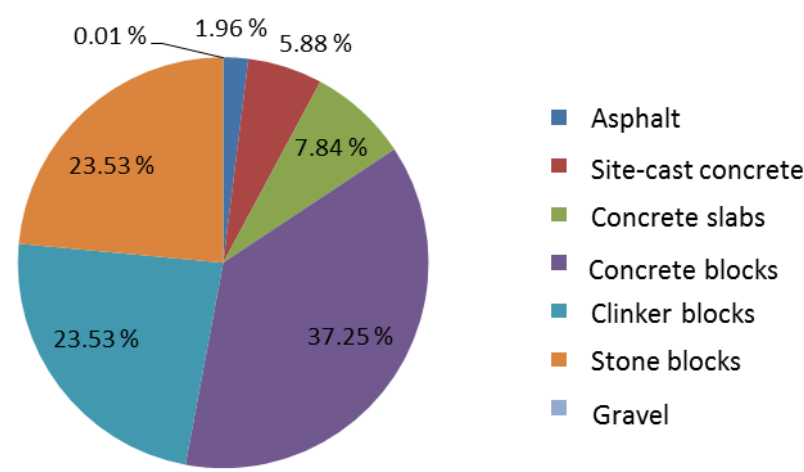

Fig. 2. Requested surface materials for pavements and footpaths according to public opinion 
Evaluating second part of the public survey it is seen that the main criteria of surface materials are aesthetics $(41 \%)$ and durability $(21.6 \%)$. The cost criterion reached only the fourth place $(9.8 \%)$ and safety in use and possibility to repair and reconstruct are not considered to be significant criteria (2\%) (Fig. $3)$.
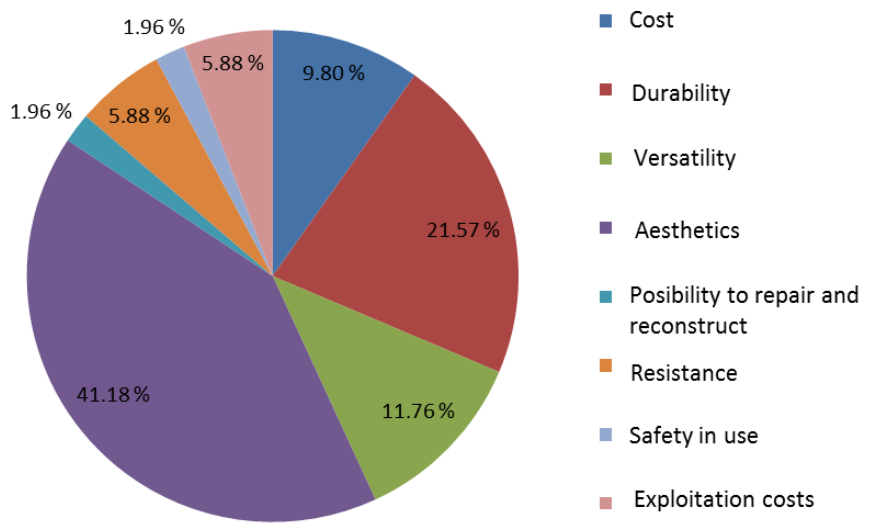

Fig. 3. Main criteria of surface materials for pavements and footpaths according to public opinion

According to economic calculations (Table 2) the most expensive pavements and footpaths are those made from stone blocks and clinker blocks, while the cheapest - gravel. The difference between the most expensive and cheapest structures is more than 12 times.

TABLE 2

Economic calculations

\begin{tabular}{|c|c|c|c|c|c|c|c|}
\hline \multirow[b]{2}{*}{ Parameter } & \multicolumn{7}{|c|}{ Surface material } \\
\hline & $\begin{array}{l}\frac{\pi}{\pi} \\
\frac{\pi}{2} \\
\frac{2}{2}\end{array}$ & 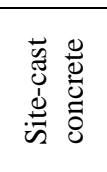 & $\begin{array}{l}\frac{\pi}{0} \\
\frac{0}{0} \\
\frac{\tilde{\sigma}}{\omega}\end{array}$ & $\begin{array}{l}\frac{\pi}{0} \\
\stackrel{0}{0} \\
0 \\
0 \\
0\end{array}$ & $\begin{array}{l}\dot{\bar{\theta}} \frac{n}{0} \\
\dot{0} \frac{0}{0}\end{array}$ & 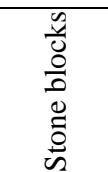 & $\begin{array}{l}\overline{0} \\
\stackrel{\pi}{0}\end{array}$ \\
\hline $\begin{array}{l}\text { Construction cost of } 100 \mathrm{~m} 2 \text { surface } \\
\text { material with first layer (without } \\
\text { kerbs), in Euros }\end{array}$ & 2430.4 & 3627.2 & 1879.8 & 2369.5 & 4604.9 & 5055.4 & 417.6 \\
\hline $\begin{array}{l}\text { Cost difference for the least } \\
\text { expensive material (gravel), } \%\end{array}$ & 5.8 & 8.7 & 4.5 & 5.7 & 11.0 & 12.1 & - \\
\hline
\end{tabular}

This distribution of cost was influenced by several factors. The supply is one of the main indicators gravel is so cheap and stone blocks are so expensive compared with the other materials. The high mechanization level in construction reduces the cost, for example in constructing asphalt or gravel pavements or footpaths. The high level of manual labour increases the cost.

According to the lifetime estimated by the "Technical Construction Regulation STR 1.12.05:2002 Usage and lifetime of the structure", the most durable material for pavements and footpaths is site-cast concrete (lifetime 40 years), followed by stone blocks (lifetime 30 years), concrete and clinker blocks (lifetime 20 years), asphalt and concrete slabs (lifetime 15 years) and the weakest materials - gravel (lifetime 10 years).
The multi-criteria analysis, using equal scores for the criteria (Fig. 4 a), shows that the optimal choice for pavements and footpaths is concrete blocks and the worst - gravel. The analysis with dominant criterion (cost) (Fig. 4 b) results in the same answer the best surface material is concrete blocks. The last on the list also is gravel, but in this test the gap between the last and next to last (asphalt) is considerably smaller. The analysis regarding the dominant criterion (aesthetics) (Fig. 4 c) shows that the best material is concrete blocks and the worst gravel. In the second and third place as in the test using equal scores for criteria are clinker blocks and stone blocks. The test regarding the dominant criterion (cost) shows that concrete slabs and clinker blocks are in the second and third place. 


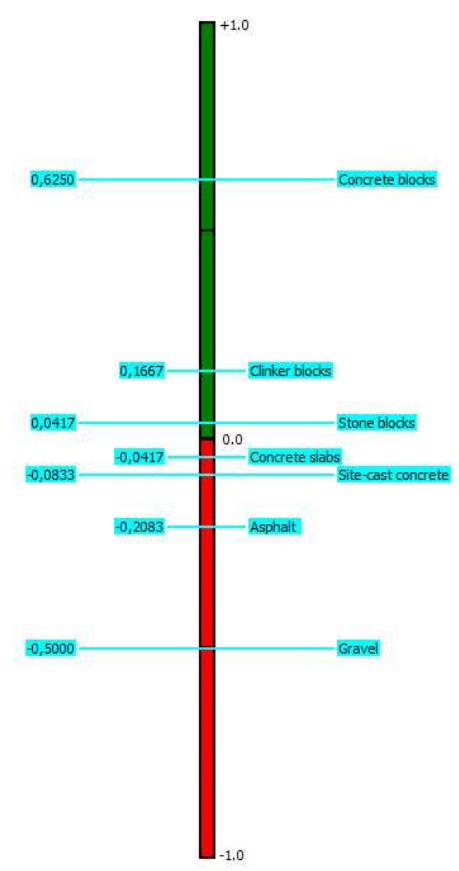

$\mathbf{a}$

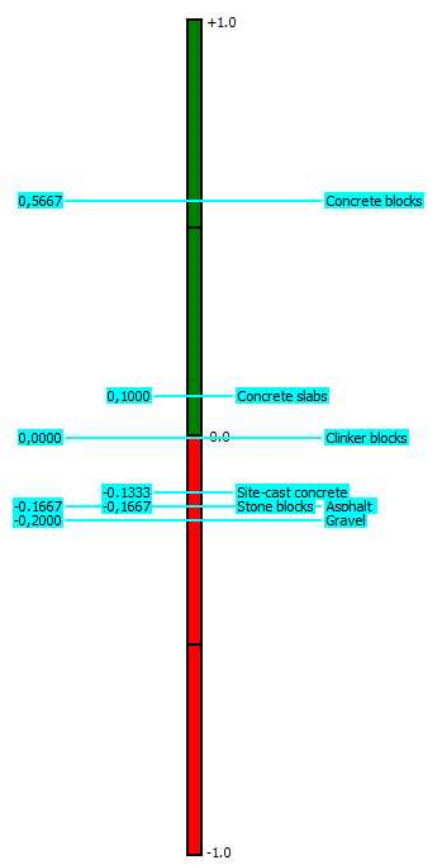

b

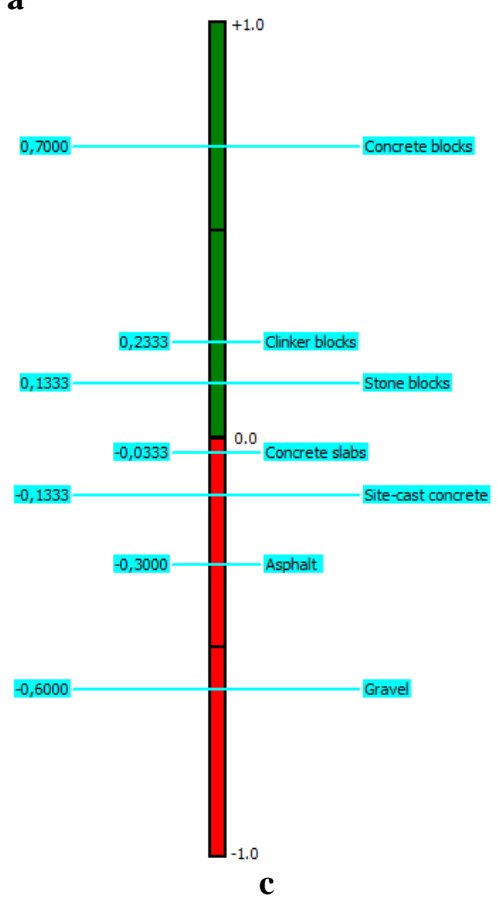

Fig. 4. Multi-criteria analysis results ( $\mathrm{a}$ - equal criteria test, $\mathrm{b}$ - dominant criterion (cost) test, $\mathrm{c}-$ dominant criterion (aesthetics) test)

\section{Conclusions}

- The majority of pavements and footpaths, which were constructed in the Soviet period, did not meet the modern day requirements. Therefore, it is not safe to use them.

- According to the public survey it is estimated that the main criteria for pavements and footpaths surface material are aesthetics $(41 \%)$ and durability $(22 \%)$. The materials which are in greatest demand are: concrete blocks (37\%), stone blocks (24\%) and clinker blocks (24\%).
- Economic calculations show that the costs of construction of pavements or footpaths differ 12 times. The most expensive pavement or footpaths are those from/with stone blocks $\left(50.55 € / \mathrm{m}^{2}\right)$ and the least expensive are gravel pavements and footpaths $\left(4.18 € / \mathrm{m}^{2}\right)$.

- According to multi-criteria analysis it is estimated that the optimal variant is pavements and footpaths with concrete blocks surface material. The worst choice is gravel. 


\section{References}

1. Aletta, F., Kanga, J., Astolfib, A., Fuda S. Differences in soundscape appreciation of walking sounds from different footpath materials in urban parks. Sustainable Cities and Society, Vol. 27 , November 2016, p. 367-376.

2. Corazza, M. V., Di Mascio, P. How to make traffic calming more walking friendly: directions to increase intersections performances for pedestrians. In: The Extra Workshop ICTCT e Safe Non-motorised Traffic. Planning, Evaluation, Behavioural, Legal and Institutional Issues, Vancouver. [online 20.04.2017] http://www.ictct.org/migrated_2014/ictct_document_nr_175_Corazza.pdf.

3. Cruisea, S. M., Huntera, R. F., Keea, F., Donnellyc, M., Ellisa, G., Tully, M. A. A comparison of road- and footpath-based walkability indices and their associations with active travel. Journal of Transport \& Health Vol.6, September 2017, p. 119-127.

4. Fuda, S., Aletta, F., Kang, J., Astolfi, A. Sound Perception of Different Materials for the Footpaths of Urban Parks. Energy Procedia, Vol.78, November 2015, p. $13-18$

5. Massart T. Footway evaluation. Transportation Research Procedia, Vol. 14, 2016, p. 2449 - 2457.

6. Pedestrian and bicycle path design guidelines, 2012 (in Lithanian).

7. Stevens, N., Salmon, P. Safe places for pedestrians: Using cognitive work analysis to consider the relationships between the engineering and urban design of footpaths. Accident Analysis \& Prevention, Vol. 72, November 2014, p. 257-266.

8. Technical Construction Regulation STR 1.12.05:2002 Usage and lifetime of the structure. (in Lithuanian).

9. Technical Construction Regulation. STR 2.03.01:2001 Structure and territories. Requirements for people with special needs.

10. Vision impairment and blindness. World health organization, 2017 [online 15.03.2017] http://www.who.int/mediacentre/factsheets/fs282/en/.

11. Visual Promethee [online 05.01.2018] http://www.promethee-gaia.net/features.htmlt 